Fecha de recepción: septiembre 2013

Fecha de aceptación: abril 2014

Versión final: septiembre 2015

\section{El funcionamiento indicial de la imagen en el nuevo cine documental latinoamericano}

Lorena Steinberg *

\begin{abstract}
Resumen: El presente trabajo busca describir algunas operaciones enunciativas que remitan a fenómenos discursivos que remitan al orden indicial en lo que respecta al aspecto que se jerarquiza en el funcionamiento de la imagen en el cine documental. Se trata de dar cuenta del efecto autentificante de la imagen, en tanto garantía de existencia del hecho. El presente artículo busca describir los mecanismos de puesta en discurso de los cuerpos, sujetos y espacios, focalizando las diversas operaciones constructivas autentificantes que se manifiestan en el nuevo cine documental latinoamericano.

El trabajo se encuadra en las conceptualizaciones de la Teoría de los Discursos Sociales de Eliseo Verón, enfoque sociosemiótico que concibe el entramado social como un sistema en el que las prácticas y las instituciones conllevan una dimensión significante. En este sentido, el cuerpo constituye una materia significante fundamental, porque conforma el pivote sobre el que se sustenta la construcción de identidades sociales.

De acuerdo a tales postulaciones, el artículo se propone dar cuenta del modo de funcionamiento de distintas operaciones verosimilizantes y autentificantes en un discurso verista como lo es el representado en el cine documental. Se considerará como central la "naturaleza" de los cuerpos mediatizados, en tanto capa metonímica de producción de sentido (Verón, 1987) y en tanto cuerpos "testigo"/ "testimonio" (impronta indicial).

En consecuencia, se definirán los atributos de los cuerpos, espacios y sujetos representados en dichos films y se establecerá la relación que los cuerpos mantienen con los espacios y objetos, siempre teniendo en cuenta los tres niveles de la configuración significante establecidos a partir de la Segunda Tricotomía peirciana (órdenes indicial, icónico y simbólico).
\end{abstract}

Palabras clave: cine documental - discursos sociales - imagen - sociosemiótica - Verón.

[Resúmenes en inglés y portugués en las páginas 60-61]

${ }^{(*)}$ Licenciada y Profesora en Ciencias de la Comunicación de la Universidad de Buenos Aires. Investigadora formada de Proyectos UBACyT con categoría IV. Asimismo, es docente de la U.B.A., IUNA, UP y de la Tecnicatura en Periodismo Deportivo del Círculo de Periodistas Deportivos -Escuela José López Pájaro. 


\section{El documental, un discurso de sobriedad}

Nichols (2007) relaciona al documental con los discursos de sobriedad (discursos de la ciencia, de la economía, de la política), que son discursos que tienen un poder instrumental, dan a conocer un argumento expositivo que tienen referentes reales y son vehículos de poder y de conciencia, apuntan a lo racional. Tiene por objetivo representar el mundo histórico, así como también se relaciona con la presunción de veracidad del enunciado. (Bitonte y Grigüelo, 2012).

El documental trabaja con la conciencia de cuestiones sociales, trata de interpelar al espectador para que devele la historia, la problemática social a la que se hace referencia. Es por esta razón que se lo relaciona con una estructura pragmática que apunta a la resolución de problemas, el documental plantea una referencia al mundo histórico pero a partir de un problema, son textos expositivos que argumentan acerca de un problema del mundo histórico, y en esa argumentación hay una estructura de problema y solución del mismo. Se trata de un montaje probatorio con una implicación lógica, una relación de causalidad entre los acontecimientos. En este marco, la palabra hablada es el sostén de la argumentación, aunque los sonidos e imágenes colaboran en la dimensión probatoria (Bitonte y Grigüelo, 2012).

\section{La función de la imagen}

Nichols (2007) también hace referencia a cuatro modalidades de representación de la realidad en el documental. La modalidad expositiva, de observación, interactiva y reflexiva. La modalidad expositiva es aquella que tiene una fuerte predominancia de una voz omnisciente, esa voz en off que trata de demostrar, a partir de las pruebas, una hipótesis. En ese contexto, la imagen funciona como ilustrativa respecto de la historia que se cuenta, constatativa. Tenía una función de mostración de los hechos.

La modalidad de observación es aquella donde el enunciador se encuentra borrado, donde la cámara funciona como observando toda la situación, trata de reproducirse el tiempo auténtico, casi no existe la voz en off, no hay entrevistas. La modalidad interactiva es la que supone una interacción, una conversación entre el realizador y los entrevistados. Se muestran los distintos puntos de vista. Adquiere distintas formas, puede estar el realizador o no, pero tiene más la modalidad de discurso. Es muy importante en esta modalidad de documental la palabra de los testigos que funcionan como pruebas. Por último, Nichols define la modalidad reflexiva. Hace una distinción entre modalidad reflexiva política y formal, y dentro de las formales, habla de distintas estrategias reflexivas. Esta última modalidad se relaciona más estrechamente con la dimensión performativa del documental. Dicha dimensión se vincula con el lugar del espectador. Nichols focaliza en las expectativas del visionado que supone un documental. A este posicionamiento del espectador lo denomina epistefilia, amor al conocimiento, la sensación de plenitud, el ansia de conocer, el poder 
develar y entender desde lo cognitivo esa demostración que plantea el documental, eso es lo que atrapa fuertemente al receptor fílmico. Este espectador es activo, realiza un proceso de inferencia lógica basada en su conocimiento previo y en el del propio texto. Este último ofrece indicios que el espectador retoma para formular una hipótesis explicativa sobre la problemática planteada por el documental.

En relación al funcionamiento de la imagen, es interesante destacar que en el documental hay un compromiso retórico en el cual el espectador espera que aquello que se muestra sea realista, es decir, que tenga que ver con los hechos realmente de ese mundo histórico que intenta mostrar. Es por esta razón que en este sentido se subraya el aspecto indicial de la imagen como garantía de la existencia del hecho, su contigüidad, su conexión dinámica con el objeto representado, siempre que sean funcionales a lo que se intenta constatar. La imagen de los objetos que se muestran no tiene una función decorativa, sino demostrativa. En el documental, el enunciador establece un contrato pedagógico. Hay una figura que posee el conocimiento y hay un enunciatario que detenta ese saber. Por ello se destaca el didactismo. Esta característica se relaciona con el hecho que en el documental, al estar vinculado con los discursos de sobriedad había una relación directa y transparente con lo real, que este discurso perseguía el objetivo de representar el mundo, la presunción de veracidad del enunciado, es decir, apuntaba al efecto de objetividad, con lo cual, lo subjetivo estaba dejado de lado. Este efecto se reforzaba al utilizar una voz en off sin cuerpo. Asimismo, porque el sujeto del enunciado no actuaba para la cámara, actuaba como si ella no estuviera presente, siempre se buscaba un efecto de objetividad.

\section{El cine documental latinoamericano: predominio de los documentales performativos}

Los documentales performativos plantean la aparición de la subjetividad, tanto desde el punto de vista del realizador como de los sujetos del enunciado. Bill Nichols plantea que hay una especie de ruptura epistemológica respecto del concepto de documental, justamente porque aparecen allí los mundos personales y de construcciones subjetivas.

Weinrichter (2005) se centra en el documental performativo y dice que en realidad el documental siempre es performativo, porque en todo proceso de construcción de sentido se produce la inscripción de la subjetividad. Desvía la atención de la cualidad referencial del documental hacia las dimensiones afectivas de la experiencia del cineasta: "yo te digo que el mundo es así". Esa sería la fórmula. En ese yo te digo queda afuera la cuestión de la verdad, la falsedad, lo ficcional. El yo te digo es incuestionable. Hablan en primera persona, siempre desde una minoría étnica, social, cultural. Ya no se trata del conocimiento de la realidad, de lo referencial, sino del conocimiento de los mundos personales, por eso esta cuestión de la subjetividad. Justamente ese yo tiene que ver con ser el representante de un margen, es desde los márgenes. El cine documental latinoamericano se inscribiría, en líneas generales, en este tipo de documental. 


\section{El estilo de Vertov, un antecedente del cine documental latinoamericano}

Es interesante destacar que Ortega (2009) visualiza en Vertov un antecedente del collage fílmico propio del documental latinoamericano, principalmente, del político, de denuncia. Ortega retoma a Karel Reisz (2009), quien define al collage como: "la rápida secuencia impresionista de imágenes inconexas, finalmente unidas por encadenado sobre impresiones, y utilizada para expresar pasos de tiempo, cambios de espacio a cualquier otra escena de transición”.

Ortega también retoma a Sánchez Biosca, quien define al collage como: "una secuencia de montaje".

En el caso del documental, lo que menciona es que esta técnica tiene bastante del collage, por la inserción de imágenes, entrevistas, filmación real sin narración, ensamblaje de elementos heterogéneos. En ese sentido, retoma al documental del collage. Lo que comenta es que hay dos estrategias: una es evidenciar el proceso de mixtura de las imágenes, y otra es neutralizar ese proceso. Obviamente, el cine tradicional o más clásico justamente trataba de invisibilizar ese proceso de amalgama, mientras que en el documental, en los casos que Ortega trabaja, se pone en evidencia ese proceso de juntada de las imágenes. Entonces, la autora dice que en realidad, el hecho de poner en evidencia la intersección de las imágenes, coincide con nuestra cultura basada en la fragmentación y en el reciclaje, que eso se adecua a la cultura audiovisual contemporánea. Los orígenes del documental y del collage tienen estrecha vinculación con las vanguardias estéticas, y específicamente con Vertov. Por un lado, porque implica concebir al cine como praxis política, en el sentido que en el cine documental hay operaciones de resignificación en el collage, donde uno utiliza determinados elementos, símbolos, imágenes, que en un contexto tienen determinada significación y en el proceso de reinserción de esa imagen, conjuntamente con otra, adquieren otra significación. Es por esta razón que el espectador debe tener conocimiento de esa significación más jerarquizada o convencional para poder entender el nuevo contexto de significación. En este marco considera al cine como un constructo imaginario, un acto creativo capaz de dar orden y significación a los fenómenos. En el caso del documental, a partir de los años setenta se integran entrevistas, imágenes de archivo y filmación real sin narración. Se produce el ensamblaje de materiales heterogéneos.

Vertov, citado por Ortega afirma: "de una vez por todas debo encontrar un aparato que no describa, sino que inscriba".

Describir tiene que ver justamente con lo que hace la narrativa tradicional en el film: caracterizar o detallar los elementos que se muestran en las imágenes. Inscribir se relaciona con el hecho de adjudicar un nuevo significado a la imagen, en otro contexto. Inscribir tiene que ver con dónde se inserta esa imagen. Asevera: "la obra se construye a partir de elementos pre- existentes a la invención creativa".

Deleuze, citado por Ortega afirma: "Vertov opondría la materia ojo a la naturaleza puño de Eisenstein".

Lo que Eisenstein sostenía como metáfora es que el cine soviético tenía por finalidad punzar, en términos de Barthes, mover el cerebro del espectador. En este sentido, tenía que tener un alto impacto o shock. En cambio, según Deleuze, Vertov "hace un tratamiento de la materia, del celuloide y de las distintas tomas, ángulos, de manera de impactar en el 
plano más perceptual, de manera que la cámara llegue a lugares donde el ojo humano no hubiese llegado".

Entonces, Deleuze hace esa distinción: por un lado, impactar con lo que se muestra, como Eisenstein, y con Vertov, en cómo se muestra, focalizando más en el aspecto enunciativo, el tratamiento que se le da a la imagen, y desde qué lugar se representa aquello que se muestra. Luego afirma: "la no ficción hace visible el montaje para lograr un impacto en la percepción, muestra las culturas y resalta la heterogeneidad, de manera tal de generar un shock cognitivo y emocional". Eso es lo que Ortega considera que Vertov trata de generar, pero a través del tratamiento de la materia, del procesamiento que se da, de cómo se hace el montaje de las distintas imágenes. En muchos casos, para Ortega lo que está haciendo Vertov es, de manera iconoclasta, tratar de parodiar toda la simbología de la representación del cine clásico: "el cine documental busca formas no naturalistas en el uso del sonido, búsqueda de sorpresa en su relación con la imagen”.

Eso también es algo que establece Vertov, que es la búsqueda de la sorpresa y el impacto. Entonces, lo que Ortega considera es que el cine documental también tiene esa finalidad: representaciones no naturalistas, en el sentido de no realistas, sino todo lo contrario, dar cuenta del propio proceso de construcción. Este procedimiento implica un giro con respecto a la modalidad del documental clásico. La imagen ya no funciona como garantía de existencia del hecho, sino como mostración de ser un constructo. Si bien podemos hablar del funcionamiento indicial en ambos casos, sus efectos son diferentes. En el primer caso se relaciona con la objetividad, y en el segundo, con la subjetividad de una impronta, de un estilo que se visualiza en evidenciar la amalgama, el collage entre elementos preexistentes. Este procedimiento se puede ejemplificar con Santiago Álvarez, que tiene cierto toque pop dentro de su cine político cubano, que convertía materias primas pre-existentes en material para el film. Ortega da dos ejemplos: No y $L B J$. No es un documental crítico respecto a cómo vivían los negros en Estados Unidos, y $L B J$ se centra en todo lo que tiene que ver con la opresión en la época de la Guerra de Vietnam. Entonces comenta, describe, una serie de imágenes en relación con el hecho de que, por ejemplo, dentro de la cabeza del presidente de Estados Unidos se insertan las imágenes de los muertos por la guerra, hace una serie de recortes y tratamientos de la imagen, donde está la lógica del insert, la edición y el montaje. Entonces, lo que Ortega considera es que este tipo de cine, que tiene que ver con el documental del nuevo cine latinoamericano, articula los dos cines que antes estaban enfrentados, el cine puño y el del material. El cine puño porque justamente tiene esta base emocional para impactar en el espectador. ¿De qué manera lo logra? A través de un tratamiento muy violento de las imágenes, una violencia estética, de la celeridad, de la yuxtaposición, de la vertiginosidad. Y por otro lado, porque articula la estética de la violencia, de qué manera se denuncia, en estos films, la violencia del imperialismo, el capitalismo, etc. Y siempre articula estos elementos apropiados y encontrados. ¿En qué sentido? Elementos encontrados por lo que decíamos antes, de articular elementos pre-existentes y darles un nuevo tratamiento, o sea, cómo se apropian estos cineastas de aquellos a la hora de elaborar el film. Este proceso del nuevo cine latinoamericano se basa en la deconstrucción y en la construcción. Deconstrucción de la imagen, por ejemplo, que el neocolonialismo ha hecho de nosotros mismos y ellos de sí mismos, y por otro lado, la nueva construcción de una realidad más crítica y palpitante, que sea de impacto para poder cuestionar esas 
formas de representación, el aspecto más reflexivo, en términos de Nichols, de dar propia cuenta de qué modo se representa aquello que, a nivel del enunciado, se muestra. Esto implica revisar los procedimientos convencionales de representación de ciertas problemáticas sociales que están naturalizados, cuando en realidad obedecen a constructos.

En la filmografía de Juan Carlos Martín, también se puede observar la heterogeneidad de los soportes de filmación, el montaje, los guiños reflexivos que apelan a la competencia y complicidad del espectador para que repiense la forma en que se representa la mexicanidad como valor.

Otro ejemplo que podemos mencionar es el documental La televisión y yo (di Telia, 2002). En este film se representa la batalla entre generaciones y grupos que pugnan por recordar u olvidar un pasado en ocasiones traumático.

Asimismo, se puede mencionar a Papá Iván (Roqué, 1999), Los Rubios (Carri, 2003) y M (Prividera, 2007), como representantes de lo que puede llamarse documentales en primera persona. Estas producciones se desarrollaron en los comienzos del siglo XXI abriendo otro cauce para los relatos de la militancia política.

\section{El "giro autobiográfico", una tendencia de los documentales del S.XXI}

El giro autobiográfico consiste en la proliferación de prácticas autobiográficas en distintos medios bajo distintos formatos, soportes y estilos. Implica re-pensar las distintas nociones de sujeto, identidad, narratividad y memoria.

Si analizamos los Films mencionados anteriormente: Los Rubios, M y Papá Iván, podemos observar que tienen varias operaciones significantes en común: efectuar un relato retrospectivo que una persona real hace de su propia existencia, poniendo el acento sobre su vida individual, su historia vivida. Asimismo, no establecer una identidad absoluta, pero sí una voluntad de identificación pragmática. El hecho de reconocer que algo es una autobiografía, como distinto de la ficción, descansa en la figura del lector y de sus conocimientos. Esto implica una concepción pragmática, las competencias, los saberes previos (Amícola, 2007). La autobiografía implica una vinculación con otro: de ahí se desprenden los temas que se vinculan con la búsqueda de la identidad, (que se construye en relación a un Otro). Arfuch también toma el concepto de identidad narrativa de Ricoeur, que supone que no hay un sujeto trascendente, un núcleo central de la personalidad que sea inmutable, sino que la identidad de un sujeto o de una comunidad, se construye en el cruce entre historia y ficción. Contar una historia de vida habla del quién de la acción. La preeminencia de lo vivencial se articula a la obsesión de certificación, de testimonio, al vértigo del directo, del tiempo real, la imagen transmitiendo bajo y para la cámara, el efecto "vida real". Empieza ahí a vislumbrar un campo relacionado con los nuevos medios. Una vivencia, una vida y un otro. Una voz que testimonia es un acto de habla que tiende hacia una respuesta. El régimen de verdad no va a estar en la referencialidad, sino en el otro, en el que la autobiografía hace creer algo. De ahí el despliegue de estrategias ficcionales de auto-representación (Iribarren, 2012). 


\section{Efectos de sentido de la autobiografía}

En el documental autobiográfico se produce un proceso de identificación con los actores sociales que participan de ese mundo, produce una valoración del mundo compartido, ya que no se trata de vidas célebres, sino de modelos sociales identificatorios basados en vidas comunes (Arfuch, 2007). Este espacio autobiográfico supone la relación indexical con el mundo histórico, la idea de que es una construcción y la presencia del cineasta. Por supuesto, también supone la experiencia de vida del autobiografiado, que tiene que ser significativa. Esto se relaciona con el modo de lectura documentalizante al que apela el cine documental según Odin:

implica un enunciador real, poder cuestionarlo en términos de verdad, así como también analizar el aporte de información que el film genera. Es por esta razón que en el film documental autobiográfico, la experiencia de vida del autobiografiado debe ser significativa en el sentido de aportar información, una nueva perspectiva sobre una problemática social (Odin, 2008).

El documental conduce al mundo de la experiencia en base a las relaciones indiciales entre las vivencias del cineasta y lo que allí expone; entonces hay una articulación entre memoria individual y memoria colectiva. Lo que lleva a pensar que toda memoria es social. Estos documentales siempre tienen una conexión con los hechos o eventos sociales. La autenticidad de lo narrado surge del cruce entre lo documental y lo testimonial. La emergencia de las memorias en estos filmes no está vinculada a la posesión de un saber sino al modo en que ellas se relacionan con un hacer. Esto se vincula con que las memorias son reconstrucciones que implican relaciones entre el mundo fílmico, el mundo real, y movilizan también procesos semióticos y cognitivos en el espectador (Iribarren, 2012). A modo de ejemplo, en Los rubios el modo en que está construida esta película no solamente remite a un cuestionamiento, a una toma de distancia con respecto al hacer o a cómo se construye un documental, sino que manifiesta o pone en evidencia esta dimensión performativa: cómo se va construyendo ese yo, cómo se va construyendo la memoria, qué se selecciona y qué se deshecha. La deconstrucción y mostración autorreflexiva del proceso de producción y los mecanismos de construcción del propio filme, son operaciones que hacen foco más en lo enunciativo que en la veracidad del enunciado. Como bien menciona Ortega:

el filme encarna, por una parte, el desafío a la capacidad de las formas tradicionales del documental de testimonio para representar la fractura personal e identitaria y la forzosa desmemoria (Albertina tenía cuatro años cuando se llevaron a sus padres, y el «yo no me acuerdo de nada» devine Leitmotiv del filme y motor de la búsqueda formal) o la memoria de quienes no quieren recordar ante la cámara. Porque su propuesta no busca la reconstrucción histórica ni la denuncia de los responsables sino su propia auto-representación (Ortega, 2007, pp. 26-27). 


\section{A modo de cierre}

Es interesante destacar que el funcionamiento indicial de la imagen ha ido modificando su estatuto. En primera instancia, el documental se apoyaba en el aspecto indical de la imagen como garantía de existencia del hecho, es decir, su aspecto factual, haciendo foco en la veracidad del enunciado.

En el caso del cine documental latinoamericano, se puede observar un corrimiento en el estatuto indicial de la imagen generar un efecto de autentificación ya no vinculado a la veracidad del enunciado, sino del la enunciación, a la puesta en evidencia de la constitución del film como discurso, como constructo. Esta tendencia se fue incrementando con el giro autobiográfico descripto en el presente trabajo: Los documentales autobiográficos permiten que los espectadores puedan escuchar relatos individuales, visitar espacios privados con cámaras subjetivas, para articular a continuación un rodaje de archivos y entrevistas que contextualizan la narrativa individual en el seno de la historia pública. La manera en que estos documentales han sido proyectados juega un papel fundamental en la formación de una esfera pública alternativa. Se caracterizan por asentar su verdad en la experiencia misma del cineasta como autor -su búsqueda, su relato de la investigación, sus frustraciones, sus límites, su aprendizaje-, que se muestra a sí mismo en la imagen, antes que en el mundo histórico, en los otros, o en el modo de representarlos (2004, p. 43). Estos documentales en primera persona no suministran una versión que clausura los hechos presentados. En razón de lo apuntado, como señala, entre otros Silvina Rival,

las imágenes del documental en primera persona coadyuvan para que la capacidad reflexiva del receptor se vea estimulada, efecto al que contribuye el no ocultamiento de los mecanismos de puesta en escena y "cierto cuestionamiento de las herramientas" prototípicas del documental, -por ejemplo, la entrevista testimonial (Rival, 2007, pp. 16-17).

Por último, el cine documental latinoamericano nos habla de nuestra sociedad, de nosotros mismos. Nos propone reflexionar sobre procesos políticos colectivos (films históricos) o individuales (films subjetivos o en primera persona). A través de ellos podemos repensarnos como sociedad, los sistemas de representación imperantes, la deconstrucción de los mismos y su resignificación en contextos alternativos.

\section{Referencias Bibliográficas}

Amícola, J. (2007). Autobiografía como autofiguración. Estrategias discursivas del Yo y cuestiones de género. Buenos Aires: Beatriz Viterbo.

Arfuch, L. (2007). Fragmentos de El espacio biográfico. Dilemas de la subjetividad contemporánea. Buenos Aires: FCE.

Bremond, C. (1982). El rol del influenciador en AA.VV.: Investigaciones retóricas II. Barcelona: Ediciones Buenos Aires. 
Bitonte, M. y Grigüelo , L. (2012). Regímenes de representación mediática: absorciones y transformaciones discursivas. Disponible en http://regimenesrepresentacion.sociales. uba.ar/intervencion-de-maria-elena-bitonte-y-liliana-griguelo/

Campo, J. (2012). Cine documental argentino. Entre el arte, la cultura y la política. 1a ed. Buenos Aires: Imago Mundi.

Cascajosa Virino, C. C. (2006) "Conclusión: reciclaje y cultura en el nuevo milenio", en El espejo deformado. Versiones, secuelas y adaptaciones en Hollywood. Sevilla: Universidad de Sevilla.

Esquenazi, J.-P. (1997). “Corps et Semiosis”, en Champs Visuels, N 7, novembre: Les images du corps.. Paris: L’Harmattan.

(1996). “Qu'est-ce qu'un discours 'vrai'? L'image 'vrai' aujourd'hui", en: Champs Visuels, $\mathrm{N}^{\circ} 2$ : Réalités de l'image. Images de la réalité (2). Paris: L’Harmattan,.

Jost, F. (1997a). "La promesse des genres” en: Réseaux. Communication, technologie, société, $\mathrm{N}^{\circ}$ 81. CNRS, Isy les Molinaux.

(1997b) "El simulacro del mundo" en: Versión, N 7. México: U.A.M.

(1989) “L' oeil caméra”, en: L’ oeil caméra Entre film et roman. Lyon: Presses Universitaires de Lyon.

Mehl, D. (1998). «La parole profane» in Penser la télévision. Jerôme Bourdon, François Jost (dir.). Nathan-INA. París. "La vida pública privada”. París: Cems-Ehess.

Nichols, B. (1997). La representación de la realidad. Barcelona: Paidós.

Odin, R. (2008). “El film familiar como documento. Enfoque semiopragmático”, en Archivos de la filmoteca Después de lo real Vol. II, (Joseph María Català y Josetxo Cerdán (eds.), No 57-58, octubre 2007/ febrero 2008.

Ortega, M. L. (2009). "De la certeza a la incertidumbre: collage, documental y discurso po lítico" en América Latina, en Piedra, papel y tijera El collage en el cine documental. Madrid: Ocho y medio.

(2007). De memorias y olvidos. El documental latinoamericano contemporáneo Cuadernos hispanoamericanos 679 .

Rangel, V. (2007). El cine argentino de hoy entre el arte y la politica. Buenos Aires: Biblos.

Ruffinelli, J. (2007). De los otros al nosotros. Familia fracturada, visión política y documental personal. al artículo fue publicado en el No 5 de la revista Kilómetro 111, noviembre.

Sánchez-Biosca, V. (1995). "Segunda Parte Atracción y fragmentación en el relato audio visual moderno", en Una cultura de la fragmentación Pastiche, relato y cuerpo en el cine y la televisión. Valencia: Filmoteca Generalitat Valenciana.

Sartora, J. y Rival, S. (editoras) (2004). Imágenes de lo real La representación de lo político en el documental argentino (pp. 141-155). Buenos Aires: Libraria.

Steinberg, L. y Varela, G. (2007). "Recorridos autentificantes de los cuerpos en programas periodísticos: algunas operaciones de La Liga y Argentinos por su nombre", co- autora junto con Lorena Steinberg, trabajo presentado en VII Congreso Nacional y II Congreso Internacional de la Asociación Argentina de Semiótica en Homenaje a Nicolás Rosa. Temporalidades El tiempo de los objetos, de los relatos, de las representaciones, de los imaginarios. Rosario, del 7 al 10 de noviembre de 2007.

Varela, G., (2003). "Identidades puestas en cuerpos. Modos de representación de identidades, cuerpos y sujetos sociales en discursos televisivos veristas" en Actas de las VII Jorna- 
das Nacionales de Investigadores en Comunicación, General Roca.

Verón, E. (1995). “Semiosis de lo ideológico y del poder”, en: Semiosis de lo ideológico y del poder. La mediatización. Buenos Aires : Fac. de Filosofía y Letras, U.B.A.

(1987). "El cuerpo reencontrado" en La semiosis social. Fragmentos de una teoría de la discursividad. Barcelona: Gedisa.

Weinrichter, A. (2005). Desvíos de lo real. El cine de no ficción. Madrid: T \& B editores.

Summary: This paper seeks to describe some declarative operations that refer to discourse phenomena that refer to the indicial order in regard to the aspect that is nested in the operation of the image in the documentary film. It is about the effect of authenticating the image as guarantee existence of the fact.

This article seeks to describe also the speech mechanisms of bodies, subjects and spaces, focusing on the various authenticating construction operations that occur in the new Latin American documentaries.

The work is framed in the conceptualizations of the Theory of Social Speeches by Eliseo Verón which sociosemiotic approach conceives the social network as a system in which the practices and institutions entail a significant dimension. In this sense, the body is a significant critical matter because forms the pivot on which the construction of social identities is based.

According to such applications, the paper aims to account for the mode of function for different operations that authenticate and gets verosimilar the veracity of the documentary film speech. It has been considered as a central issue, the "nature" of mediated bodies as metonymic layer of meaning production (Verón, 1987) and as both "witness " body and " testimony" body (indexical imprint) .

Consequently, we will define the attributes of bodies, spaces and subjects represented in these films and the relationship that the bodies remain with spaces and objects, taking into account the three levels of the significant configuration set from the Second Peircean trichotomy (indexical, iconic and symbolic orders) .

Key words: documentary film - picture - social speeches - sociosemiotics - Verón .

Resumo: O trabalho descreve operações enunciativas que lembram fenômenos discursivos que remitem à ordem indicial no aspecto que se hierarquiza no funcionamento da imagem no cinema documental. Trata-se de dar conta do efeito de auto - identificação da imagem, como garantia de existência do feito.

$\mathrm{O}$ artigo procura descrever os mecanismos de posta em discurso dos corpos, sujeitos e espaços, focalizando as diversas operações construtivas autentificantes que se manifestam no novo cinema documental latino americano.

O trabalho enquadra-se nas conceitualizações da teoria dos discursos sociais de Eliseo Verón, enfoque sócio-semiótico que concebe a trama social como um sistema no qual as práticas e as instituições tem uma dimensão significante. Neste sentido, o corpo constitui 
uma matéria significante fundamental, porque conforma a base sobre a qual se sustenta a construção de identidades sociais.

Segundo tais postulações, o artigo se propõe dar conta do modo de funcionamento de diferentes operações que dão veracidade e autenticidade em um discurso realista como é aquele representado no cinema documental.

Definem-se os atributos dos corpos, espaços e sujeitos representados nesses filmes e se estabelece a relação que os corpos mantém com os espaços e objetos, sempre tendo em conta os três níveis da configuração significante estabelecidos a partir da Segunda Tricotomia Peirciana (ordens indicial, icônico e simbólico).

Palavras chave: cinema documental - discursos sociais - imagem - sociosemiótica - Verón 